\title{
Influence of Thermochemical Treatment on the Surface Properties of Finish Turned Wire Arc Sprayed 17Cr Steel Coatings
}

\author{
Pia Kutschmann ${ }^{1, *}$, Thomas Lindner ${ }^{1}\left(\mathbb{D}\right.$, Hendrik Liborius ${ }^{2}$, Thomas Grund ${ }^{1}$, Andreas Schubert ${ }^{2} \mathbb{E}$ \\ and Thomas Lampke ${ }^{1}$ D \\ 1 Materials and Surface Engineering Group, Institute of Materials Science and Engineering, \\ Chemnitz University of Technology, D-09107 Chemnitz, Germany; th.lindner@mb.tu-chemnitz.de (T.L.); \\ thomas.grund@mb.tu-chemnitz.de (T.G.); thomas.lampke@mb.tu-chemnitz.de (T.L.) \\ 2 Professorship Micromanufacturing Technology, Institute for Machine Tools and Production Processes, \\ Chemnitz University of Technology, D-09107 Chemnitz, Germany; \\ hendrik.liborius@mb.tu-chemnitz.de (H.L.); andreas.schubert@mb.tu-chemnitz.de (A.S.) \\ * Correspondence: pia.kutschmann@mb.tu-chemnitz.de
}

check for

updates

Citation: Kutschmann, P.; Lindner, T.; Liborius, H.; Grund, T.; Schubert,

A.; Lampke, T. Influence of

Thermochemical Treatment on the Surface Properties of Finish Turned Wire Arc Sprayed 17Cr Steel Coatings. Appl. Sci. 2021, 11, 6520. https:// doi.org/10.3390/app11146520

Academic Editor:

Tomasz Chmielewski

Received: 1 June 2021

Accepted: 11 July 2021

Published: 15 July 2021

Publisher's Note: MDPI stays neutral with regard to jurisdictional claims in published maps and institutional affiliations.

Copyright: (c) 2021 by the authors. Licensee MDPI, Basel, Switzerland. This article is an open access article distributed under the terms and conditions of the Creative Commons Attribution (CC BY) license (https:/ / creativecommons.org/licenses/by/ $4.0 /)$.
Abstract: Structural features of thermal spray coatings, e.g., porosity, can be beneficial as oil retention volumes in tribological systems in order to improve emergency running properties. While thermal spray coatings can already have a considerable degree of porosity depending on the coating conditions, the finish machining, e.g., by turning, has a significant influence on the final surface properties. Effects like near-surface deformation and subsequent closing of pores during the machining process should be prevented. In the present study, the influence of thermochemical surface hardening on the surface topography of wire arc sprayed $17 \mathrm{Cr}$ steel layers after finish turning was investigated. Successful surface hardening by gas nitriding was shown by light microscopic and phase analyses. The surface properties after the various treatment steps were characterized by the surface roughness parameters $R a$ and $R z$, the valley void volume $V v v$, and the Abbott curves. A rise of the valley void volume can be beneficial in tribological applications in which a suitable oil retention volume is required. Accordingly, a thermochemical treatment combined with an appropriate subsequent finishing process is suitable to significantly influence the surface properties of thermal spray steel coatings.

Keywords: $17 \mathrm{Cr}$ steel; gas nitriding; machining; surface properties; valley void volume; wire arc spraying

\section{Introduction}

Thermal spray coatings are characterized by a heterogeneous microstructure comprised of oxides, pores, and cracks due to the deposition process and the chosen thermal and kinetic parameters of the applied thermal spray process. Furthermore, the mentioned imperfections result in increased surface roughness. While open porosity is a disadvantage in corrosion prevention applications, in tribological systems, it can improve the emergency running properties by acting as an oil reservoir [1-3]. In order to achieve a suitable surface topography of thermal spray coatings in tribological systems, finish machining is necessary. Hence, for the desired open porosity, lubrication and contamination effects must be avoided during machining.

Finishing of thermal spray coatings using tools with geometrically defined cutting edges is often limited due to the constitution of the deposited layer. Hard abrasive particles such as oxides and carbides, as well as the coating porosity resulting from the spraying process, cause rapid cutting tool wear [4-10]. Another problem is the comparably low coating adherence to the substrate. Hence, the selection of the cutting material and the adjustment of the machining parameters to the coating microstructure are essential to achieve the targeted surface properties. 
In finish boring experiments of iron-based thermal spray coatings, the influence of the cutting material on the tool wear was analyzed [4,5]. Of the indexable inserts used, two were CBN-tipped (high and low content of boron nitride, respectively), one diamondtipped, one was cermet, and one was cemented carbide. Machining was performed with constant cutting parameters $\left(v_{c}=300 \mathrm{~m} / \mathrm{min}, f=0.1 \mathrm{~mm}, a_{p}=0.25 \mathrm{~mm}\right)$. After a cutting length of $390 \mathrm{~m}$, the cermet tool displayed the highest tool wear, with a measured flank wear land width of about $2.1 \mathrm{~mm}$. Using CBN with $50 \%$ boron nitride bounded by a ceramic binder, diamond, or cemented carbide as the cutting material resulted in similar flank wear land widths of about $1 \mathrm{~mm}$. Significantly lower tool wear (flank wear land width of $0.1 \mathrm{~mm}$ ) was achieved by finish boring with CBN-tipped tools with $90 \%$ boron nitride and a metallic binder.

Liborius et al. focused on the adjustment of the cutting parameters while turning ironbased thermal spray coatings $[6,10,11]$. The cutting parameters, particularly the cutting speed, have a significant influence on the quantity of pulled-out coating material. This effect results in the generation of a high oil retention volume. Experimental investigations addressed the influence of the cutting speed in turning of Fe17Cr2Ni0.2C coatings produced by atmospheric plasma spraying. CBN-tipped indexable inserts having a high content of boron nitride and a metallic binder were used. During the experimental investigation, the cutting speed $v_{c}$ was adjusted while being kept within a range of $100 \mathrm{~m} / \mathrm{min}$ to $400 \mathrm{~m} / \mathrm{min}$. Feed $f(0.05 \mathrm{~mm})$ and depth of cut $a_{p}(0.05 \mathrm{~mm})$ were kept unchanged during dry machining. After turning, the surfaces were generally characterized by feed marks, pores, microcracks, and a high valley void volume due to pulled-out coating material. These findings corroborate the results represented in [5-7]. Increasing the cutting speed caused a decreased proportion of pulled-out coating material and subsequently lower surface roughness values due to the higher shear zone temperature. However, the simultaneous increase in tool wear resulted in minimal values for $R a$ and $R z$ after machining with a cutting speed of $v_{c}$ of $300 \mathrm{~m} / \mathrm{min}$. These results were confirmed in experimental investigation of the turning of Ni5Al thermal spray coatings by varying cutting speeds $v_{\mathcal{C}}(30 \mathrm{~m} / \mathrm{min}-260 \mathrm{~m} / \mathrm{min})$, depths of cut $a_{p}(0.05 \mathrm{~mm}, 0.12 \mathrm{~mm})$, and feeds $f(0.05 \mathrm{~mm}-0.2 \mathrm{~mm})$ [8].

In addition to the cutting speed, the feed also influences the surface properties in the machining of sprayed coatings. A higher feed results in increased kinematic surface roughness. Due to the aforementioned surface imperfections, the measured roughness is generally higher than the calculated value. Investigations regarding the influence of the feed $f$ in the turning of iron-based atmospheric plasma sprayed coatings in the range of $0.025 \mathrm{~mm}$ to $0.15 \mathrm{~mm}$ showed the expected increase of $R a$ and $R z$ [11]. However, the proportion of pulled-out coating material decreased for feeds above $0.1 \mathrm{~mm}$.

Deformation of the surface is observed in connection with the machining of ductile materials. Such deformation often leads to smearing effects or to the storage of removed material within the porosity; finishing parameter adjustment can only partially mitigate these issues. One solution could be the surface hardening of coatings, which would reduce heterogeneous material states, arising, e.g., from oxidation during the thermal spray deposition process, and material ductility. Surface hardening has successfully been demonstrated for thermal spray steel coatings. Depending on the treatment parameters, both interstitial solid solution hardening and precipitation formation can be achieved during nitriding, nitrocarubizing, and carburizing of stainless steel coatings [12-18]. In addition, boronizing can also lead to a precipitation formation of particularly high hardness and temperature resistance $[19,20]$.

Mostly, AISI 316L coatings deposited by high-velocity oxygen fuel spraying (HVOF), atmospheric plasma spraying (APS), or cold gas spraying (CGS) were nitrided or nitrocarburized by a thermochemical plasma process. The surface hardening only reaches depths of less than $50 \mu \mathrm{m}[13,14,17]$. Park et al. also considered 17-4PH and AISI 410 stainless steel coatings and detected precipitations of $\mathrm{CrN}, \mathrm{Fe}_{3} \mathrm{~N}$, and $\mathrm{Fe}_{4} \mathrm{~N}$ in the plasma-nitrided coatings [14]. A gas nitriding of AISI 316L HVOF sprayed coatings was investigated by 
Lindner et al. [16]. The precipitation layer, consisting of $\mathrm{Fe}_{4} \mathrm{~N}$ and $\mathrm{CrN}$, reached a depth of more than $100 \mu \mathrm{m}$, which was explained by the penetration of the gaseous enrichment media through the coating porosity. Compared to the as-sprayed condition, a significant hardness increase, which averages $860 \mathrm{HV} 0.01$, and a superior wear resistance were shown. Park et al. even reported hardness values up to 1300 HV0.01 for plasma-nitrided steel coatings [14].

A novel approach is using the surface properties of hardened coatings, particularly the increased hardness of the surface layer, for mechanical finishing. The precipitation formation should prevent smearing effects as well as provoke pulled-out coating material. In this way, the valley void volume should be increased and used for the storage of lubricants. Chao et al. showed the positive effects of surface hardening via plasmanitration of stainless steel with the intention of preparing extremely smooth surfaces with subsequent machining by single-point diamond turning [21].

The research work presented investigates the effect of thermochemical surface hardening of the wire arc sprayed $17 \mathrm{Cr}$ steel coatings, comparable with EN 1.4122, on the resultant geometrical surface quality after finish turning. The aim of the process combination is an increase in proportion and volume of pulled-out coating material for use as possible oil reservoirs.

\section{Materials and Methods}

\subsection{Arc Sprayed 17Cr Steel Coatings}

The oxidation-resistant $17 \mathrm{Cr}$ steel wire with a diameter of $1.6 \mathrm{~mm}$ and a nominal composition in the mass fraction in \% of $\mathrm{Cr} 15-17$, Mo 1, Si 0.5, Mn <1, and Fe balanced (50.62, GTV GmbH, Luckenbach, Germany) was selected as the coating material. The coatings were deposited on low carbon steel (EN S235) samples with dimensions of $\varnothing$ $40 \mathrm{~mm} \times 8 \mathrm{~mm}$ by using the arc spray unit VISU ARC 350 (Oerlikon Metco, Wohlen, Switzerland). Prior to the coating process, the sample face was grit blasted with corundum EK F $24(-800 \mu \mathrm{m}+600 \mu \mathrm{m})$, an air pressure of 2.5 bar, a nozzle-surface distance of $150 \mathrm{~mm}$, and an angle of $70^{\circ}$. Afterward, the substrates were cleaned in an ethanol ultrasonic bath. The coating thickness in the as-sprayed state was adjusted to the range from $350 \mu \mathrm{m}$ to $400 \mu \mathrm{m}$ by the number of layers. The optimized arc spray parameters are given in Table 1 . The parameter, assessed in an unpublished pretest, with a low coating thickness per layer revealed no delamination or spalling even at the sample edge during the subsequent gas nitriding or machining process.

Table 1. Arc spray parameters for $17 \mathrm{Cr}$ steel wire.

\begin{tabular}{cc}
\hline Spray Parameter & Value \\
\hline Current $(\mathrm{A})$ & 120 \\
Voltage $(\mathrm{V})$ & 30 \\
Atomizing gas pressure (bar) & 4.5 \\
Spraying distance $(\mathrm{mm})$ & 150 \\
Offset $(\mathrm{mm})$ & 8 \\
Surface velocity $(\mathrm{m} / \mathrm{s})$ & 0.6 \\
Coating thickness per layer $(\mu \mathrm{m})$ & 35 \\
\hline
\end{tabular}

\subsection{Nitriding and Machining of the Arc Sprayed 17Cr Steel Coatings}

The coatings were post-treated by a thermochemical gas nitriding process, which was applied on coated samples in the as-sprayed and faced surface condition. The samples were treated in an industrial gas nitriding process (Härterei REESE Chemnitz GmbH \& Co. KG, Chemnitz, Germany) in order to achieve a precipitation hardening with nitriding depths of 0.3 to $0.5 \mathrm{~mm}$ for bulk materials. The process was carried out in an ammonia atmosphere without previous surface activation following the parameters given in [16].

The machining was carried out on a lathe Condor VC (Weiler GmbH, Emskirchen, Germany) by face turning. As tools, CBN- and PCD-tipped indexable inserts were used. 
The tool geometry of the CBN-tipped tool is defined by DCGW 11T304 and the PCDtipped indexable insert by DCGT 11T304 (both PREMUS, Precitool, Neuenstein, Germany). Table 2 summarizes the facing parameters used. The coatings were machined in three passes applying minimum quantity lubrication.

Table 2. Machining parameters for coatings post-treatment.

\begin{tabular}{ccccc}
\hline $\begin{array}{c}\text { Machining } \\
\text { Parameter }\end{array}$ & $\begin{array}{c}\text { Cutting } \\
\text { Material }\end{array}$ & $\begin{array}{c}\text { Cutting Speed } \\
v_{\mathrm{C}}(\mathrm{m} / \mathbf{m i n})\end{array}$ & Feed $f(\mathrm{~mm})$ & $\begin{array}{c}\text { Depth of Cut } \\
\boldsymbol{a}_{\mathrm{P}}(\mathbf{m m})\end{array}$ \\
\hline f1 & CBN & & 0.12 & \\
f2 & CBN & 62 & 0.17 & $\sim 0.05$ \\
f3 & PCD & & 0.12 & \\
\hline
\end{tabular}

\subsection{Characterization of the Arc Sprayed $17 \mathrm{Cr}$ Steel Coatings}

The arc sprayed $17 \mathrm{Cr}$ steel coatings were evaluated concerning their microstructure, phase composition, and surface properties using qualitative and quantitative methods. Cross-sections were prepared in the as-sprayed and gas nitrided conditions in order to characterize their microstructure. The etching with the alcoholic nitric acid Nital exposed the nitriding depth. The optical microscope GX51 (Olympus, Shinjuku, Japan) equipped with a SC50 camera (Olympus, Shinjuku, Japan) was used for image capturing. The phase determination was performed by X-ray diffraction (XRD) using a D8 DISCOVER diffractometer from Bruker AXS (Billerica, MA, USA). The samples were measured with a line focus in Bragg-Brentano geometry (10 mm irradiated sample length) and a Lynxeye XE$\mathrm{T}$ detector. Co K $\alpha$ radiation (U: $40 \mathrm{kV}$; I: $40 \mathrm{~mA}$ ) was used to measure in a diffraction angle

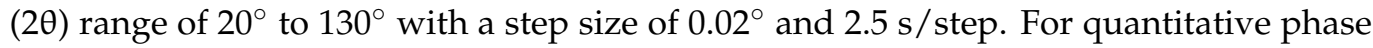
determination, the Rietveld method was applied using the program TOPAS (Bruker AXS, Billerica, MA, USA). Additionally, the microhardness in the cross-sections (Vickers hardness HV0.3) was measured with a Wilson Tukon 1102 device (Buehler, Uzwil, Switzerland). Average hardness values of at least five indentations, as well as hardness depth profiles, were prepared with the same load. A distance of $50 \mu \mathrm{m}$ for each indentation in combination with an alternating indentation pattern was chosen to create the hardness depth profiles. Furthermore, the hardness of the single phases was evaluated using a UNAT nano-indenter (ASMEC GmbH, Radeberg, Germany) with a Berkovich tip in the quasi-continuous stiffness measurement mode (QCSM) with a maximum load of $0.25 \mathrm{mN}$. The nanohardness values were determined at the maximum indentation depth.

The quantitative surface properties were determined using a stylus instrument hommeletamic T8000 (Jenoptik AG, Jena, Germany). The roughness profiles were recorded in the direction of the feed motion with a stylus having a $5 \mu \mathrm{m}$ radius and cut-off wavelength $\lambda c$ of $2.5 \mu \mathrm{m}$ resulting in a measured length of $12.5 \mathrm{~mm}$ and a traversed length of $15 \mathrm{~mm}$. The selection was carried out in accordance to DIN ISO 11562. For every treatment condition, two samples with five measurements evenly distributed around the specimen perimeter were analyzed. The filtered profiles were calculated in regards to the average surface roughness $R a$ and the surface roughness depth $R z$.

The surface topography before and after face turning was analyzed by laser scanning microscopy (LSM) with a Keyence VK-X200 device (Keyence, Osaka, Japan). For a detailed investigation of the coating surface after gas nitriding, additional images with a scanning electron microscope (SEM) LEO 1455VP (Zeiss, Jena, Germany) were recorded. The LSM data were further processed with the image analyzing software MountainsMap ${ }^{\circledR}$ (Digital Surf, Besançon, France) to calculate the Abbott curves and valley void volume Vvv of all faced samples. The valley void volume $V v v$ correlates to the oil retention volume in possible tribological applications. This enabled the comparison of the proportion of the aforementioned surface defects between different post-treated surfaces. For the determination, areas of the size $750 \mu \mathrm{m} \times 750 \mu \mathrm{m}$ were analyzed. A form filter (polynomial 2nd order) was applied, and the periodic kinematic roughness profile was removed from the surface using "line orientation". The Abbott curve of the resulting surface was characterized 
by a small core roughness, and consequently, the tangent in this area had a small slope. Therefore, the lower material ratio (Smr2) was determined, which gave an approximated and reproducible value for the proportion of pores and pulled-out material. The Smr 2 was used as the upper boundary for calculating the valley void volume $(\mathrm{Vvv})$. The filtering of the surfaces is described in detail in [6].

\section{Results}

\subsection{Coating Characterization}

The coating microstructures in the as-sprayed and gas nitrided conditions are shown in Figure 1. The as-sprayed coating presents the typical structure of a wire arc sprayed deposit comprising of steel and oxide lamellas with embedded pores (Figure 1a,b). Small oxide particles might break out during the cross-sectional preparation, causing an overall porosity content of $3.6 \%$.

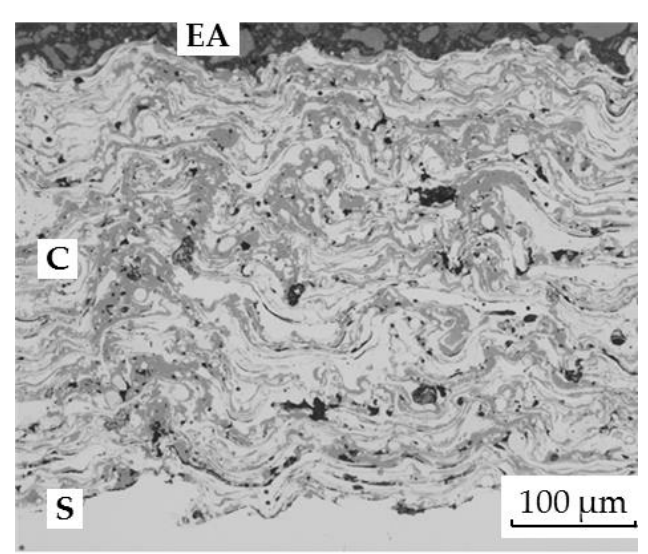

(a)

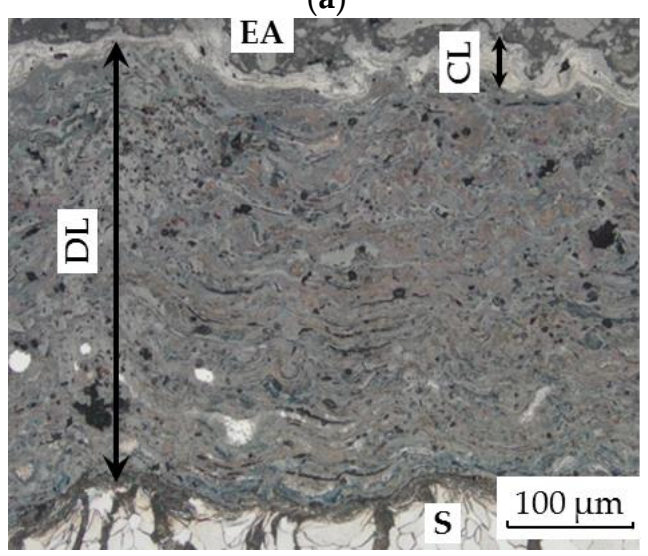

(c)

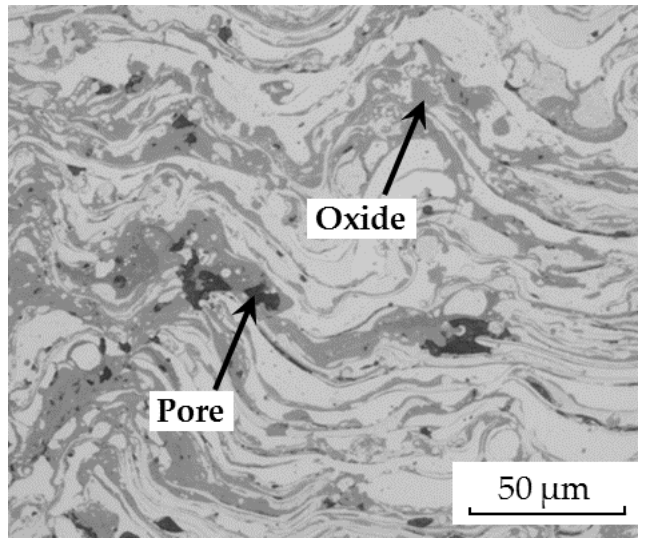

(b)

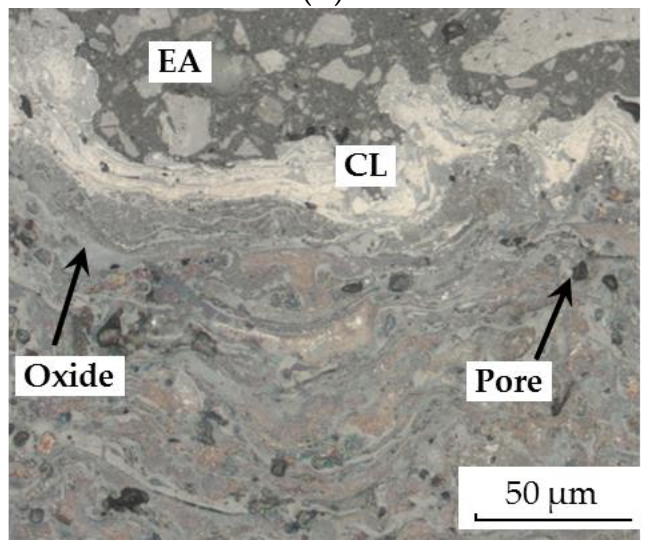

(d)

Figure 1. Light microscopic cross-section images of arc sprayed $17 \mathrm{Cr}$-steel coatings: (a,b) as-sprayed; (c,d) gas nitrided after etching with Nital (EA = embedding agent, $\mathrm{C}=$ coating, $\mathrm{S}=$ substrate, $\mathrm{CL}=$ compound layer, $\mathrm{DL}=$ diffusion layer $)$.

Figure 1c,d illustrates the gas nitrided coating after etching with Nital. At the surface, a white layer appears with an average thickness of $25 \mu \mathrm{m} \pm 9 \mu \mathrm{m}$. This coating area indicates the compound layer. Underneath, the diffusion layer, also called the precipitation layer in the case of alloyed steels, formed up to the substrate. The through porosity in the arc sprayed coatings ensures the penetration and coatings enrichment by the gaseous nitriding media in the applied thermochemical treatment process.

XRD analysis demonstrates the phase compositions of the $17 \mathrm{Cr}$ steel coatings after finishing in the untreated and gas nitrided state (Figure 2). Before thermochemical treatment (finished f1), the quantitative coating's phase composition results in a mass fraction of 
$63 \%$ ferrite, $14 \%$ retained austenite, and $23 \%$ magnetite $\left(\mathrm{Fe}_{3} \mathrm{O}_{4}\right)$ using the Rietveld method. The gas nitriding leads to the formation of hexagonal $\varepsilon-\mathrm{Fe}_{3} \mathrm{~N}$ and face-centered cubic $\gamma^{\prime}-\mathrm{Fe}_{4} \mathrm{~N}$ phases in the compound layer (finished 1 and gas nitrided). After machining, approximately $150 \mu \mathrm{m}$ coating material had been removed. According the XRD analysis (gas nitrided and finished f1), the diffusion layer consists of a mass fraction of $73 \%$ ferrite and $27 \%$ magnetite; $\mathrm{FeN}$ or $\mathrm{CrN}$ phases are not detected. However, the etched cross-section (Figure 1c,d) suggests that submicron $\mathrm{CrN}$ precipitations in the diffusion layer were formed [22].

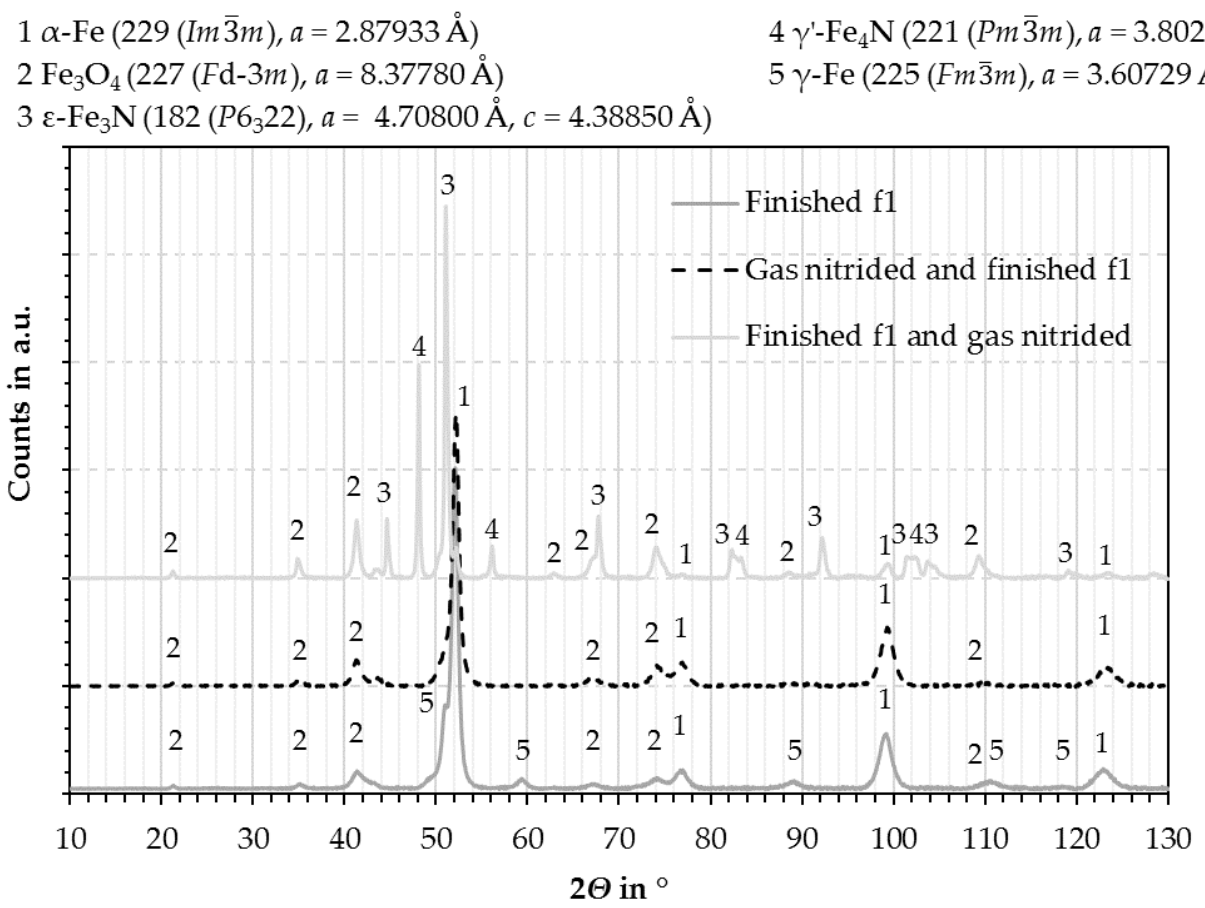

Figure 2. X-ray diffraction diagrams of the arc sprayed $17 \mathrm{Cr}$ steel coatings in the finished and gas nitrided state.

The comparison of the hardness values confirms the formation of precipitates in the diffusion layer (Table 3). The as-sprayed $17 \mathrm{Cr}$ steel layer exhibits an average hardness of 461 HV0.3, which exceeds the coating's hardness values of 250 to 370 HV0.3 of thermal spray steel coatings produced with less oxidation [17,18,23]. After gas nitriding, the hardness of the diffusion layer averages 556 HV0.3. In Figure 3, the hardness depth profile indicates that the hardness within the layer is independent of the surface distance, not taking into account the compound layer. Additionally, the hardness was determined by nanoindentation (Table 3), which revealed a $25 \%$ harder thin compound layer than the diffusion layer. In contrast to that, the magnetite phase possesses a lower hardness than the diffusion layer; however, the precipitation-hardened and oxide areas exhibit similar hardness values on average. As a result, the hardness of the coating showed less heterogeneity in the surface hardened state, not considering the compound layer, compared to the as-sprayed state. 
Table 3. The hardness of the arc sprayed 17Cr-steel coatings in the as-sprayed and gas nitrided condition.

\begin{tabular}{cccc}
\hline \multicolumn{2}{c}{ Hardness } & As-Sprayed & Gas Nitrided \\
\hline Microhardness (HV0.3) & Total coating area & $461 \pm 50$ & $556 \pm 114^{1}$ \\
\hline \multirow{2}{*}{$\begin{array}{c}\text { Nanoindentation hardness } \\
(\mathrm{GPa})\end{array}$} & $\begin{array}{c}\text { Compound layer (CL) } \\
\text { Steel lamellas/ }\end{array}$ & - & $10 \pm 2.5$ \\
& Diffusion layer (DL) & $6 \pm 1$ & $8 \pm 1$ \\
& Oxide & $7 \pm 1$ & \\
\hline
\end{tabular}

${ }_{1}$ only diffusion layer.

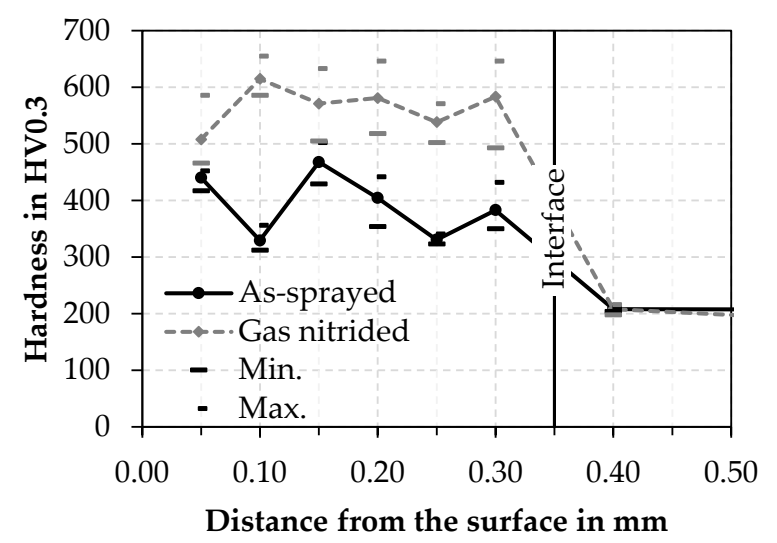

Figure 3. Hardness depth profiles of the arc sprayed $17 \mathrm{Cr}$ steel coating in the as-sprayed and gas nitrided state.

\subsection{Comparison of the Surface Properties after Gas Nitriding and Facing}

The influence of the surface hardening and the machining process on the surface properties is illustrated in Figure 4 using LSM images of the sample surfaces. The finished surfaces (Figure 4a-d) are characterized by feed marks, opened pores, cracks, and a high valley void volume resulting from coating material pulled-out during the cutting process. The opened pores reflect the coating porosity, but the cracks can also be caused by either the gas nitriding or the finish-machining step.

Using the same machining parameter (f1) before and after nitriding leads to a significant increase in the quantity of pulled-out coating material in the surface hardened condition (Figure $4 a, b$ ). The heterogeneous hardness distribution in the just-faced coatings promotes deformation, while the diffusion layer predominantly chips. An increase of the feed or change of the cutting material from CBN to PCD (Figure 4c,d) reduces the volume of pulled-out material. Similar findings were identified in [11]. In contrast to that, the finished and gas nitrided sample (Figure $4 \mathrm{e}, \mathrm{f}$ ) shows the characteristic nubby surface of the hard compound layer. Predominately, the nitrides were formed at the edge of pores and in cracks, and cover the surface nearly completely.

The topography of the different treatment states recorded by laser scanning microscopy is shown in Figure 5 by means of Abbott curves. According to the diagram, a significant increase in the volume fraction of the valleys could be achieved by the process combination of gas nitriding and subsequent face turning. The greatest increase was achieved when using a CBN-tipped indexable insert at a low feed (machining parameter f1), which coincides with the parameter used for facing the as-sprayed coating. Furthermore, the curves show a good correlation with the surface images shown in Figure 4. As a result, an increase of the $R z$-value can be related to an increase in pulled-out material areas (Table 4). While, for surface-hardened variants, the profile heights decreased slightly, and generally smaller topographical differences were observed, surface hardening in the finished turned state has no influence on the proportion of removed material. The grown nitrides slightly increased the profile heights. However, the roughness values $R a$ and 
$\mathrm{Rz}$ are almost comparable to the finished surface in the as-sprayed condition (machining parameter f1, Table 4).

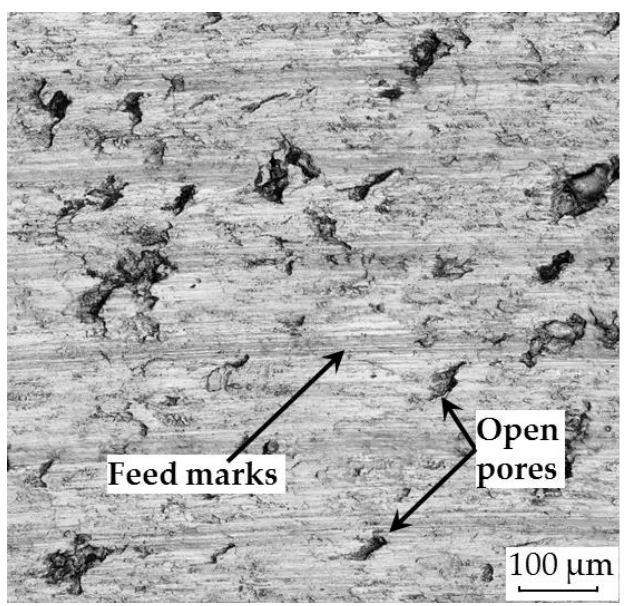

(a)

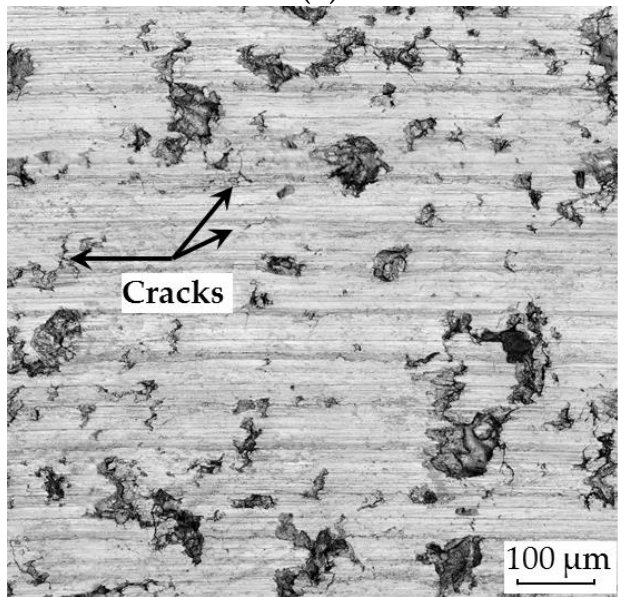

(c)

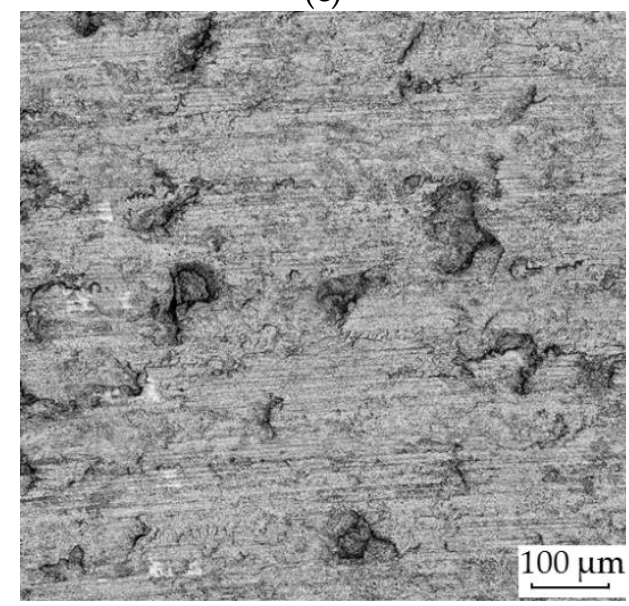

(e)

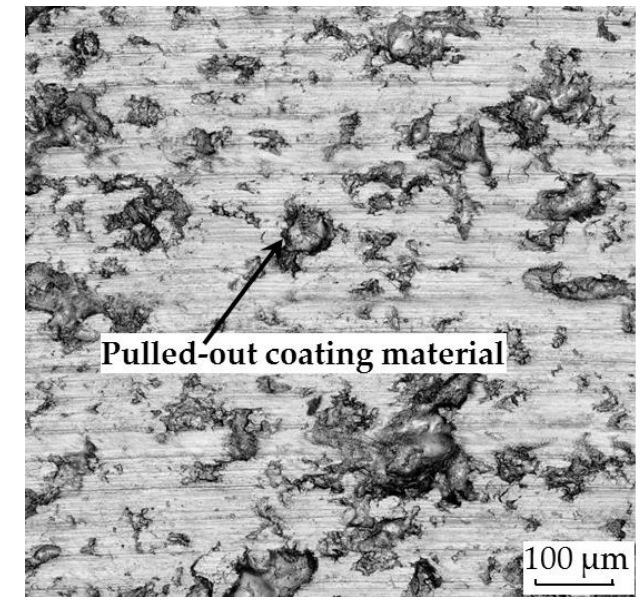

(b)

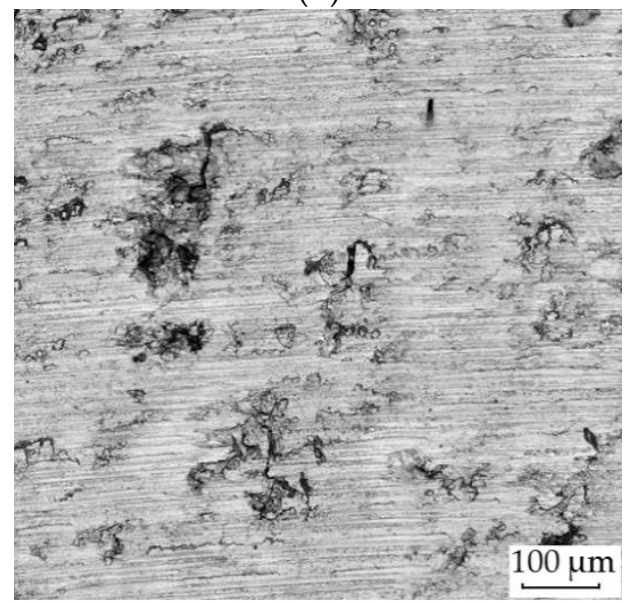

(d)

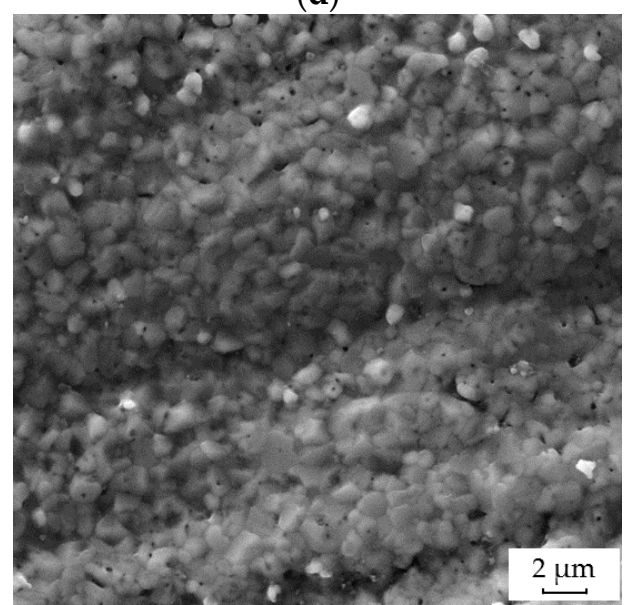

(f)

Figure 4. Laser scanning microscope images of the finished surfaces of arc sprayed 17Cr-steel coatings: (a) finished with machining parameter $\mathrm{f1}$; (b) gas nitrided and finished with f1; (c) gas nitrided and finished with $\mathrm{f} 2$; (d) gas nitrided and finished with f3; (e,f) finished with f1 and gas nitrided with (f) showing an SEM image recorded with the secondary electrons (SE) detector. 


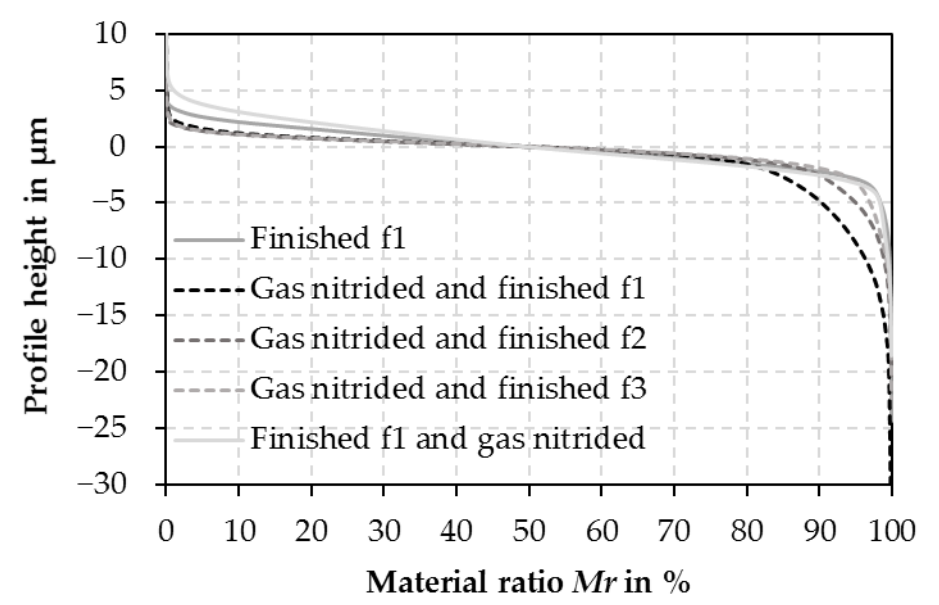

Figure 5. Abbott curves of the finished surfaces before and after gas nitriding.

Table 4. Surface roughness of the arc sprayed $17 \mathrm{Cr}$-steel coatings before and after different post-treatments.

\begin{tabular}{cccc}
\hline Surface State & Machining Parameter & \multicolumn{2}{c}{ Roughness $(\boldsymbol{\mu m})$} \\
& & $\mathbf{R} \boldsymbol{z}$ & $83 \pm 11.5$ \\
As-sprayed & - & $14 \pm 1.9$ & $7.8 \pm 1.1$ \\
Finished & $\mathrm{f} 1$ & $1.3 \pm 0.1$ & $19 \pm 2.7$ \\
Gas nitrided and finished & $\mathrm{f} 1$ & $1.8 \pm 0.4$ & $17 \pm 2.4$ \\
Gas nitrided and finished & $\mathrm{f} 2$ & $1.6 \pm 0.3$ & $20 \pm 4.2$ \\
Gas nitrided and finished & $\mathrm{f} 3$ & $1.4 \pm 0.2$ & $8 \pm 1.8$ \\
Finished and gas nitrided & $\mathrm{f} 1$ & & \\
\hline
\end{tabular}

The determined values of the valley void volume $V v v$ shown in Table 5 confirm the previously described behavior regarding the proportion of pulled-out coating material. The lowest proportions are reached after machining the as-sprayed coating. After nitriding and subsequent machining, the lowest proportion of pulled-out coating particles is achieved when using a PCD-tipped indexable insert and a small feed (machining parameter $\mathrm{f} 3$, $f=0.12 \mathrm{~mm}$ ). This relationship cannot be derived from the standard roughness values $R a$ and $R z$ summarized in Table 4, which reveal higher roughness values for the machining parameter $\mathrm{f} 2$. When machining nitrided coatings using CBN-tipped tools, higher Vvovalues are reached. Machining the coating with the lower feed increases the proportion of the mentioned surface defects strongly. Similar results regarding the machining with different feeds are also shown in [11]. The higher feed results in higher components of the resultant force while machining due to the increased cross-section of the undeformed chip. Simultaneously, however, the tool-workpiece contact area also increases. Hence, there is a changed distribution of these force components, resulting in less pulled-out coating material. Based on the results, an additional surface hardening process in combination with adjusted machining parameters can significantly influence the surface properties of thermal spray coatings. A superior wear behavior of the coatings due to the surface hardening still has to be proven.

Table 5. Determined valley void volume $(V v v)$ after machining.

\begin{tabular}{ccc}
\hline Surface State & Machining Parameter & Valley Void Volume $V v v\left(\mathbf{m L} / \mathbf{m}^{2}\right)$ \\
\hline Finished & $\mathrm{f} 1$ & 0.296 \\
Gas nitrided and finished & $\mathrm{f} 1$ & 1.19 \\
Gas nitrided and finished & $\mathrm{f} 2$ & 0.485 \\
Gas nitrided and finished & $\mathrm{f} 3$ & 0.334 \\
Finished and gas nitrided & $\mathrm{f} 1$ & 0.279 \\
\hline
\end{tabular}




\section{Conclusions}

The influence of a thermochemical surface hardening process on the final machining behavior of thermal spray steel coatings was investigated. The $17 \mathrm{Cr}$ steel coatings deposited by wire arc spraying were successfully gas nitrided, resulting in a compound and precipitation layer. Due to the coating through porosity, a high nitrogen penetration up to the substrate was achieved, which results in a uniform hardness within the precipitation layer compared to the as-sprayed condition. The machining by facing was carried out before and after nitriding. The resulting surface layer was evaluated by tactile and optical surface characterization methods. It was shown that surface hardening led to larger material ratios below the core roughness according to the Abbott curves. Compared to the just-faced condition, the topographical differences were insignificant. In summary, thermochemical treatment of thermal spray steel coatings influenced the cutting behavior. Thus, the possibility of adjusting functional surfaces more specifically is given. Tribological systems with emergency running property requirements could be improved in a targeted manner. However, it has still to be proven whether the surface hardening influences the wear properties of the treated and finished coatings under lubricating conditions.

Author Contributions: Conceptualization, P.K., T.L. (Thomas Lindner), and T.G.; funding acquisition, T.G.; investigation, P.K. and H.L.; project administration, T.G. and T.L. (Thomas Lampke); supervision, T.L. (Thomas Lindner), A.S. and T.L. (Thomas Lampke); validation, P.K. and H.L.; writing-original draft, P.K. and H.L.; writing-review and editing, T.L. (Thomas Lindner) and H.L. All authors have read and agreed to the published version of the manuscript.

Funding: This center has received taxpayer-funded financial support in accordance with the Saxony State Parliament Representatives' agreed regional budget as part of the High-Performance Center "Smart Production and Materials". The publication of this article was funded by the Chemnitz University of Technology.

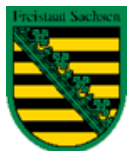

Institutional Review Board Statement: Not applicable.

Informed Consent Statement: Not applicable.

Data Availability Statement: Nor applicable.

Acknowledgments: The authors thank Marc Pügner for conducting and the support in the XRD and nanoindentation measurements.

Conflicts of Interest: The authors declare no conflict of interest.

\section{References}

1. Edtmayer, J.; Loesch, S.; Hick, H.; Walch, S. Comparative study on the friction behavior of piston/bore interface technologies. Automot. Engine Technol. 2019, 4, 101-109. [CrossRef]

2. Barbezat, G.; Schmid, J. Plasmabeschichtung von Zylinderkurbelgehäusen und ihre Bearbeitung durch Honen. MTZ Mot. Z. 2001, 62, 314-320.

3. Bobzin, K.; Ernst, F.; Zwick, J.; Schlaefer, T.; Cook, D.; Nassenstein, K.; Schwenk, A.; Schreiber, F.; Wenz, T.; Flores, G.; et al. Coating Bores of Light Metal Engine Blocks with a Nanocomposite Material using the Plasma Transferred Wire Arc Thermal Spray Process. J. Ther. Spray Technol. 2008, 17, 344-351. [CrossRef]

4. Ding, K.; Sasahara, H. Study on the machining of iron-based thermal spray coating for sleeveless engine cylinder. Adv. Mat. Res. 2012, 472-475, 991-996. [CrossRef]

5. Ding, K.; Sasahara, H.; Adachi, S.; Nishimura, K. Investigations on the Cutting Process of Plasma Sprayed Iron Base Alloys. Key Eng. Mater. 2012, 447-448, 991-996. [CrossRef]

6. Liborius, H.; Paczkoswki, G.; Nestler, A.; Grund, T.; Mehner, T.; Schubert, A.; Lampke, T. Influence of cutting speed on the surface properties in turning of $\mathrm{Fe} 17 \mathrm{Cr} 2 \mathrm{Ni} 0.2 \mathrm{C}$ iron based thermally sprayed coatings. In Proceedings of the International Conference on Competitive Manufacturing, Stellenbosch, South Africa, January 30-1 February 2019; pp. 317-323. 
7. Clauß, B.; Liborius, H.; Lindner, T.; Löbel, M.; Schubert, A.; Lampke, T. Influence of the cutting parameters on the surface properties in turning of a thermally sprayed AlCoCrFeNiTi coating. Procedia CIRP 2020, 87, 19-24. [CrossRef]

8. López de Lacalle, L.N.; Gutiérrez, A.; Lamikiz, A.; Fernandes, M.H.; Sánchez, J.A. Turning of thick thermal spray coating. J. Ther. Spray Technol. 2001, 10, 249-254. [CrossRef]

9. Grund, T.; Paczkowski, G.; Lampke, T.; Liborius, H.; Nestler, A.; Schubert, A. Finish turning of FeCr17Ni2C0.2 iron-based sprayed coatings: Influence of substrate preparation, cutting speed and feed on the coating and surface properties. J. Ther. Spray Technol. 2019, 29, 308-318. [CrossRef]

10. Liborius, H.; Nestler, A.; Paczkowski, G.; Schubert, A.; Grund, T.; Lampke, T. Machining of Fe17Cr2Ni0.2C iron based thermally sprayed coatings by turning with special interest to the influence of the depth of cut. In Proceedings of the Special interest Group meeting on Advancing Precision in Additive Manufacturing, Nantes, France, 16-18 September 2019; pp. 100-103.

11. Liborius, H.; Nestler, A.; Paczkowski, G.; Schubert, A. Surface integrity of FeCr17Ni2C0.2 iron based thermally sprayed coatings with special respect to the influence of the feed. MM Sci. J. 2019, 4, 3220-3227. [CrossRef]

12. Wielage, B.; Rupprecht, C.; Lindner, T.; Hunger, R. Surface modification of austenitic thermal spray coatings by low-temperature carburization. In Proceedings of the International Thermal Spray Conference \&Exposition, Long Beach, CA, USA, 11-14 May 2015.

13. Adachi, S.; Ueda, N. Formation of S-phase layer on plasma sprayed AISI 316L stainless steel coating by plasma nitriding at low temperature. Thin Solid Film. 2012, 523, 11-14. [CrossRef]

14. Park, G.; Bae, G.; Moon, K.; Lee, C. Effect of plasma nitriding and nitrocarburizing on HVOF-sprayed stainless steel coatings. J. Ther. Spray Technol. 2013, 22, 1366-1373. [CrossRef]

15. Lindner, T.; Mehner, T.; Lampke, T. Surface modification of austenitic thermal-spray coatings by low-temperature nitrocarburizing. In Proceedings of the 18th Chemnitz Seminar on Materials Engineering-18. Werkstofftechnisches Kolloquium, Chemnitz, Germany, 10-11 March 2016.

16. Lindner, T.; Kutschmann, P.; Löbel, M.; Lampke, T. Hardening of HVOF-sprayed austenitic stainless steel coatings by gas nitriding. Coatings 2018, 8, 348. [CrossRef]

17. Adachi, S.; Ueda, N. Wear and Corrosion Properties of cold-sprayed AISI 316L coatings treated by combined plasma carburizing and nitriding at low temperature. Coatings 2018, 8, 456. [CrossRef]

18. Kutschmann, P.; Lindner, T.; Börner, K.; Reese, U.; Lampke, T. Effect of adjusted gas nitriding parameters on microstructure and wear resistance of HVOF-sprayed AISI 316L coatings. Materials 2019, 12, 1760. [CrossRef] [PubMed]

19. Löbel, M.; Lindner, T.; Hunger, R.; Berger, R.; Lampke, T. Precipitation hardening of the HVOF sprayed single-phase high-entropy alloy $\mathrm{CrFeCoNi.} \mathrm{Coatings} \mathrm{2020,} \mathrm{10,} \mathrm{701.} \mathrm{[CrossRef]}$

20. Lindner, T.; Löbel, M.; Hunger, R.; Berger, R.; Lampke, T. Boriding of HVOF-sprayed Inconel 625 coatings. Surf. Coat. Techn 2020, 404, 126456. [CrossRef]

21. Chao, C.L.; Chen, C.C.; Chang, C.J.; Dong, H.S.; Ma, K.J.; Hsu, W.Y.; Huang, K.C.; Chao, C.W. Single-Point Diamond Turning of Plasma -Nitrided Stainless Steel. KEM 2007, 364-366, 601-606. [CrossRef]

22. Liedtke, D. Wärmebehandlung von Eisenwerkstoffen, 2 Nitrieren und Nitrocarburieren, 7th ed.; Mesenhold, H.J., Ed.; Expert Verlag GmbH: Tübingen, Germany, 2018.

23. Zhao, L.; Lugscheider, E. Influence of the spraying process on the properties of 316L stainless steel coatings. Surf. Coat. Technol. 2002, 162, 6-10. [CrossRef] 